\title{
Blood transfusion trends in obstetrics at the Federal Teaching Hospital in Abakaliki, South-East Nigeria
}

This article was published in the following Dove Press journal:

International Journal of Women's Health

II July 2013

Number of times this article has been viewed

\author{
Osaheni L Lawani' \\ Chukwuemeka A lyoke ${ }^{2}$ \\ Azubuike K Onyebuchi' \\ 'Department of Obstetrics and \\ Gynecology, Federal Teaching Hospital, \\ Ebonyi State, Nigeria; ${ }^{2}$ Department of \\ Obstetrics and Gynecology, University \\ of Nigeria Teaching Hospital, Enugu \\ State, Nigeria
}

Background: Obstetric hemorrhage has been repeatedly implicated as a leading cause of maternal mortality in Nigeria, yet there are very few studies that evaluate the practice of blood transfusion in obstetrics as a life saving measure.

Objectives: The aim of this study was to evaluate the practice of obstetric blood transfusion, the mean decision-transfusion interval, and the outcome in parturients who had blood transfusions.

Methods: This was a prospective descriptive study conducted at the Federal Teaching Hospital, Abakaliki, South-East Nigeria, between 1st January, 2012 and 31st December, 2012. Statistical analysis was done using SPSS version 15.0 for Windows.

Results: Out of 151 parturients who received blood transfusion, 141/151 (97.4\%) were knowledgeable about blood transfusion, while only 10/151 (2.6\%) had no knowledge of it. The hospital was the source of information for 120/151 (80.8\%) of the participants. Blood transfusion rate was $7.04 \%$ of all parturients. The mean decision-transfusion interval was $12.0 \pm 4.3$ hours. All participants were transfused with either whole blood or sedimented cells. The mean number of blood units transfused was $1.77 \pm 0.93$ units. The indications for transfusion were: anemia, 109/151 (72.2\%); shock, 13/151 (8.6\%); postpartum hemorrhage, 23/151 (15.2\%); antepartum hemorrhage, $6(4 \%)$. Six (4\%) women died; mortality was due to renal failure in 3/6 (50\%) and disseminated intravascular coagulopathy in $3 / 6(50 \%)$. These deaths were due to delays and difficulty in securing blood for transfusion, while those who got transfused on time were salvaged with minimal morbidity, 21/151 (14\%), or with no morbidity, 130/151 (86\%).

Conclusion: Excessive blood loss and anemia still complicate most pregnancies in our practice and the mean decision-transfusion interval is unacceptably long with debilitating maternal morbidity and mortality that can be improved with safe and effective blood transfusion with minimal or no risk.

Keywords: blood, hemorrhage, obstetrics, transfusion, trend

\section{Introduction}

Blood transfusion in obstetric practice has been found and documented to be life-saving and obstetric conditions associated with the need for blood transfusion can lead to morbidity and mortality if not managed appropriately. In sub-Saharan Africa, blood supply is critically inadequate and severe hemorrhage is a leading cause of maternal deaths. Each year more than 528,000 women worldwide die from complications of pregnancy and childbirth, up to $80 \%$ of these maternal deaths are directly due to five complications: hemorrhage, sepsis, eclampsia, ruptured uterus from obstructed labor, and complications of abortion. ${ }^{1}$ Although reliable information about the individual medical causes of maternal mortality is scarce, especially in sub-Saharan Africa, hemorrhage during labor, delivery, and postpartum period accounts for one-third of
Correspondence: OL Lawani Department of Obstetrics and Gynecology, Federal Teaching Hospital, Abakaliki, Ebonyi State, Nigeria

Tel +234803669 I209

Fax +234708900 9130

Email lawkins2000@yahoo.com 
all obstetric deaths in the world and is the leading cause of maternal deaths in Africa (34\%) and Asia (31\%). ${ }^{2}$ Obstetric hemorrhage is a leading cause of maternal morbidity and mortality in both developed and developing world. ${ }^{3}$ The World Health Organization estimates that hemorrhage at the time of delivery complicates around $10 \%$ of all live births globally. ${ }^{3}$ It is the leading direct cause of maternal death (28\%), followed by sepsis, hypertensive disorders, and obstructed labor. ${ }^{3}$

Nigeria makes up only $1.7 \%$ of the total world population, but accounts for about $10 \%$ of the global estimate of maternal mortality mainly related to hemorrhage $(25 \%)$, hence its significant contribution to the country's high maternal mortality rate estimated at $800-1000$ per 100,000 live births. ${ }^{46}$ Nigeria thus ranks among the nations with the highest number of maternal deaths. ${ }^{6}$

Blood transfusion is not without risk. The major risk associated with blood transfusion is a patient receiving an "incorrect" blood component. The increasingly important issues in blood transfusion are adverse events or risk such as blood transfusion reactions, infections, the development of red blood cell antibodies, and iron overload in different organs of the body from frequent blood transfusion. Transfusion reactions could occur due to allergic (hypersensitivity) reactions following blood transfusion. Other common concerns include acquiring blood borne infections such as hepatitis $\mathrm{B}$ and $\mathrm{C}$, human immunodeficiency virus, and malaria. ${ }^{7-9} \mathrm{~A}$ third risk may result from inherited red blood cell traits which results in rejection of blood cells due to the development of antibodies. ${ }^{9}$

This study aims to review the practice of blood transfusion in obstetric care in a major referral hospital in SouthEast Nigeria with a view to contributing to the formulation of an effective blood transfusion policy to combat the high rate of mortality associated with obstetric hemorrhage in the study area and other developing nations with similar clinical settings.

\section{Material and methods}

This was a prospective descriptive study conducted at the Federal Teaching Hospital, Abakaliki (FETHA), Ebonyi State, South-East Nigeria between 1st January, 2012 and 31 st December, 2012. Informed written consent was obtained from all participants and ethical clearance was also obtained from the hospital ethical committee. A consecutive sample of women who presented for obstetric care and had blood transfusions during the study period was taken. Data were collected using an interviewer-administered questionnaire by trained doctors. Data were collected at the point of admission for those who were admitted with complications or at the point of diagnosis of complications for those who developed complications after being admitted. Information sought in the questionnaire included biodemographic characteristics of patients, awareness of the possibility of blood transfusion before and after delivery, reason for blood transfusion, number of units transfused, and outcome of blood transfusion including any complications. All subjects and transfused blood were screened for human immunodeficiency virus types I and II and hepatitis B and C pretransfusion and 3 months after transfusion. Those who defaulted or had risky exposure to these infections during follow up were excluded from the study. However, participants were not screened for cytomegalovirus (CMV) infection due to lack of facilities. Statistical analysis was performed using Statistical Package for the Social Sciences version 15.0 for Windows (SPSS; IBM Corporation, Armonk, NY, USA) and the process involved descriptive statistics. Main outcome variables were the proportion of women who had transfusions and were aware of the possibility of transfusion and indications before the procedure, the proportion of all patients who had blood transfusion, and the major types of blood products transfused. Secondary outcome measures were the mean decision-transfusion interval as well as the prevalence of major complications of blood transfusion.

\section{Results}

A total of 151 women participated in this study. The mean age of participants was $27.97 \pm 5.30$ years. Table 1 shows that the majority were Christians (145/151; 96\%), 3/151 (2\%) were Muslims, and 3/151 (2\%) practiced traditional African religion. Among the Christians, Pentecostal denomination accounted for 63/145 (41.7\%), Catholics 60/145 (39.7\%), Anglicans 22/145 (14.6\%), none were Jehovah witnesses.

Table 1 also shows that 38/151 (25.8\%), 36/151 (23.2\%), 42/151 (28.0\%), and 35/151 (23.0\%) had none, primary, secondary, and tertiary education respectively and that $65 / 151$ (43\%) resides in urban areas, while 86/151 (57\%) resided in rural areas. There was no significant difference between the antenatal booking status, with booked and unbooked participants accounting for $75 / 151(49.7 \%)$ and $76 / 151(50.3 \%)$, respectively as depicted in Table 2 .

Table 3 shows that awareness of blood transfusion was very high $(147 / 151 ; 97.4 \%)$, while only $4 / 151(2.6 \%)$ had no knowledge of it. In the vast majority, the hospital (122/151; $80.8 \%$ ) was the source of information while other sources were: friends in 33/151 (21.9\%), electronic media in $17 / 151$ 
Table I Biodemographic characteristics of participants

\begin{tabular}{|c|c|c|}
\hline Characteristics & Number $(n=15 I)$ & Percentage (\%) \\
\hline \multicolumn{3}{|l|}{ Age (years) } \\
\hline Less than 20 & 10 & 6.6 \\
\hline $20-24$ & 46 & 30.4 \\
\hline $25-29$ & 41 & 27.2 \\
\hline $30-34$ & 30 & 19.9 \\
\hline $35-39$ & 23 & 15.2 \\
\hline 40 and above & I & 0.7 \\
\hline Total & 151 & 100 \\
\hline \multicolumn{3}{|l|}{ Educational level } \\
\hline None & 38 & 25.8 \\
\hline Primary & 36 & 23.2 \\
\hline Secondary & 42 & 28.0 \\
\hline Tertiary & 35 & 23.0 \\
\hline Total & 151 & 100 \\
\hline \multicolumn{3}{|l|}{ Marital status } \\
\hline Married & 120 & 79.5 \\
\hline Single & 28 & 18.5 \\
\hline Separated & 3 & 2.0 \\
\hline Divorced & 0 & 0.0 \\
\hline Total & $15 \mid$ & 100 \\
\hline \multicolumn{3}{|l|}{ Occupation } \\
\hline Farmer & 24 & 15.9 \\
\hline Hairdresser & 2 & 1.3 \\
\hline Trader & 30 & 19.9 \\
\hline Public servant & 60 & 39.7 \\
\hline Student & 20 & 13.3 \\
\hline House wife & 15 & 9.9 \\
\hline \multicolumn{3}{|l|}{ Religion } \\
\hline Christian & 145 & 96 \\
\hline Muslims & 3 & 2 \\
\hline $\begin{array}{l}\text { Traditional African } \\
\text { religion }\end{array}$ & 3 & 2 \\
\hline Total & 151 & 100 \\
\hline \multicolumn{3}{|c|}{ Christian denominations } \\
\hline Catholics & 60 & 39.7 \\
\hline Pentecostal & 63 & 41.7 \\
\hline Anglican & 22 & 14.6 \\
\hline Jehovah witness & 0 & 0.0 \\
\hline Total & 145 & 96 \\
\hline \multicolumn{3}{|l|}{ Residence } \\
\hline Urban & 65 & 43 \\
\hline Rural & 86 & 57 \\
\hline Total & 151 & 100 \\
\hline
\end{tabular}

(11.3\%), school in 13/151 (8.6\%), church in 8/151 (5.3\%), and book/newspaper in 7/151 (4.6\%), as shown in Table 3. A total of 2146 pregnant women delivered in the facility during the study period. One hundred and twenty-seven (84\%) delivered at term, while 24/151 (16\%) had preterm deliveries. Vaginal delivery was the most common mode of delivery in $82 / 151(54.3 \%)$, followed by caesarean section in $54 / 151$ (35.8\%), while 15/151 (9.9\%) had exploratory laparotomy for ruptured uteri. There were nine instrumental deliveries all of which were by vacuum extraction. A total of $43 / 151(28.5 \%)$
Table 2 Antenatal booking status and parity

\begin{tabular}{lll}
\hline & Number $(\mathbf{n}=\mathbf{~ I ~ 5 ~ I ) ~}$ & Percentage (\%) \\
\hline Booking status & & \\
Booked & 75 & 49.7 \\
Unbooked & 76 & 50.3 \\
Total & 151 & 100 \\
Parity & & \\
Para 0 & 67 & 44.4 \\
Para I & 25 & 16.6 \\
Para 2 & 15 & 10.0 \\
Para 3 & 25 & 16.6 \\
Para 4 & 20 & 13.4 \\
Para 5 and above & 9 & 6.0 \\
\hline
\end{tabular}

of the parturients had episiotomy, while 18/151 (11.9\%) sustained genital tract laceration comprised of 12/151 (7.9\%) and 6/151 (2\%) 1st and 2nd degree lacerations, respectively. There were no 3rd or 4th degree lacerations. Amongst the transfused parturients, blood loss was $>500 \mathrm{~mL}$ in $99 / 151$ $(65.6 \%)$ in those who had vaginal delivery and $>1000 \mathrm{~mL}$ in 52/151 (42.1\%) in those who had surgery for abdominal delivery or ruptured uteri.

The transfusion rate was $7.04 \%(151 / 2146)$. The mean decision-transfusion interval was $12.0 \pm 4.3$ hours. All participants were transfused with blood either as whole blood (70\%) or sedimented cells (30\%) with 67/151 (44.4\%), $66 / 151$ (43.7\%), and 18/151 (11.9\%) receiving 1,2 , and $\geq 3$ units of blood, respectively, as shown in Table 4. Four hundred and fifty milliliters of whole blood constitutes a unit of blood. The mean number of blood units transfused was $1.77 \pm 0.93$ units. The minority $(62 / 151 ; 41 \%)$ received blood transfusion for a life threatening obstetric emergency within 24 hours of admission, while the majority (89/151; $59 \%$ ) had the procedure after 24 hours of presentation. Most of the blood units were transfused postpartum (109/151; $72 \%)$, while only $42(28 \%)$ were transfused antepartum. The indications for transfusion as shown in Table 5, were anemia

Table 3 Level of awareness and source of information

\begin{tabular}{lll}
\hline & Number $(\mathbf{n}=\mathbf{~ I 5 ~ I ) ~}$ & Percentage (\%) \\
\hline Awareness & 147 & 97.4 \\
Aware & 4 & 2.6 \\
Unaware & $15 \mathrm{I}$ & 100 \\
Total & & \\
Source of information & 122 & 80.8 \\
Hospital & 33 & 21.9 \\
Friends & 17 & 11.3 \\
Electronic media & 13 & 8.6 \\
School & 8 & 5.3 \\
Church & 7 & 4.6 \\
Books/newspaper & & \\
\hline
\end{tabular}


Table 4 Blood products transfused and amount transfused

\begin{tabular}{lll}
\hline & Number $(\mathbf{n}=\mathbf{~ I 5 ~ I )}$ & Percentage (\%) \\
\hline Blood products & & \\
Whole blood & 106 & 70.0 \\
Sedimented cells & 45 & 30.0 \\
Total & $15 \mathrm{I}$ & 100 \\
Units of blood transfused & \\
I unit & 67 & 44.4 \\
2 units & 66 & 43.7 \\
$\geq 3$ units & 18 & 11.9 \\
\hline
\end{tabular}

$(109 / 151 ; 72.2 \%)$ with postpartum anemia accounting for 98/109 (90\%) of these and antepartum anemia for 11/109 (10\%), postpartum hemorrhage (PPH) 23/151 (15.2\%), shock $13 / 151(8.6 \%)$, and ante partum hemorrhage $6 / 151(4 \%)$ in the presence of maternal hemodynamic instability and fetal compromise (fetal heart rate irregularities). All those who had shock also had severe anemia with their packed cell volume $<12 \%$. The pretransfusion pack cell volume revealed that $21 / 151$ (14\%) had mild anemia, 52/151 (34.3\%) moderate anemia, and 78/151 (51.7\%) severe anemia. The majority of those with anemia $(136 / 151 ; 90.2 \%)$ had it corrected after transfusion before discharge from the hospital, while 15/151 (9.8\%) still had mild anemia before discharge despite being transfused, which was due to the inability of the patient to provide the required amount of blood needed to optimally correct their anemia. The mean pack cell volume pre and post transfusion was $16 \% \pm 3.82 \%$ and $32 \% \pm 5.12 \%$, respectively. A few $(6 / 151 ; 4 \%)$ had transfusion reactions, all of which were hypersensitivity reactions in the form of urticaria with chills and rigors, while another 6/151 (4\%) had malaria infection following blood transfusion. These complications were noted in those who had multiple blood transfusions. There were no other reported cases of other blood borne infections. Strict adherence to correct labeling of blood products, as well as cross-match and administration procedures, are helpful in preventing such transfusion reactions.

The index pregnancy was complicated in 82/151 (54.3\%) of patients, the complications were antepartum hemorrhage

Table 5 Indications for transfusion

\begin{tabular}{lll}
\hline & Number $(\mathbf{n}=\mathbf{~ 1 5}$ I) & Percentage (\%) \\
\hline Indications & & \\
Anemia & 109 & 72.0 \\
$\quad$ Antepartum anemia & 11 & 7.3 \\
$\quad$ Postpartum anemia & 98 & 64.7 \\
Postpartum hemorrhage & 23 & 15.2 \\
Shock & 13 & 8.6 \\
Antepartum hemorrhage & 6 & 4.0 \\
\hline
\end{tabular}

(APH); 35/151 (22.9\%) mainly from placenta previa; 32/151 $(20.8 \%)$ and abruption placenta; $3 / 151$ (2.1\%) between 28-34 weeks gestation requiring multiple transfusion and all the women surviving without any major maternal morbidity or mortality. Other complications were PPH; 46/151 (30.2\%), ruptured uterus; $22 / 151$ (14.5\%), severe preeclampsia; 18/151 (12\%), malaria and anemia; 16/151 (10.8\%), ectopic pregnancy; 15/151 (9.6\%). Post-partum morbidity occurred in 21/151 (14\%) of participants, morbidity include hypovolemic shock; 50/151 (33\%), wound infections; 45/151 (30\%), puerperal sepsis; $35 / 151$ (23\%), anemic heart failure; 12/151 (7.6\%), renal failure; 5/151 (3.2\%) and disseminated intravascular coagulopathy; 5/151 (3.2\%) as shown in Table 6. Six of the one hundred and fifty-one participants died, this represents $4 \%$ of the sample. The deaths were as a result of complications of renal failure; $3 / 6(50 \%)$ and disseminated intravascular coagulopathy; $3 / 6(50 \%)$. The mean duration of hospital stay was $8.25 \pm 5.12$ days.

\section{Discussion}

The knowledge of blood transfusion was high amongst the subjects. This may have been due to the fact that counseling was offered before transfusion and information on transfusion was also given during health talks at every antenatal visit. This is also supported by the fact that the majority cited the hospital as their source of information on blood transfusion.

Several studies have shown that obstetric care is still very poor in this part of the world and that hemorrhage and anemia necessitating blood transfusion complicates most pregnancies in Africa. ${ }^{1,2,8,10}$ This is pertinent because many women managed in the studied institution present with obstetric morbidity and mortality related to hemorrhage and anemia.

The transfusion rate of $7.04 \%$ in this study is far higher than rates of $0.16 \%$ to $2.6 \%$ reported by other researchers. ${ }^{11-18}$

Table 6 Complications associated with blood loss and anemia

\begin{tabular}{lll}
\hline & Number $(\mathbf{n}=\mathbf{~ I 5 ~ I ) ~}$ & Percentage (\%) \\
\hline Complications & & \\
Hypovolemic shock & 50 & 33.0 \\
Wound infection & 45 & 30.0 \\
Puerperal sepsis & 35 & 23.0 \\
Anemic heart failure & 12 & 7.6 \\
Renal failure & 5 & 3.2 \\
Disseminated intravascular & 5 & 3.2 \\
coagulopathy & & \\
Death & 6 & 4.0 \\
Total & 151 & 100 \\
\hline
\end{tabular}


Obstetric hemorrhage still remains a major issue for safe motherhood in Nigeria as shown in this study where $65.6 \%$ and $42.1 \%$ of our sample who had vaginal delivery and surgery for abdominal delivery/exploration, respectively, had PPH and thus received blood transfusion as a life saving measure, this is at variance with reports from some developed countries. ${ }^{16,17}$ Since several studies in Nigeria have reported $\mathrm{PPH}$ as being responsible for about $25 \%$ or more of maternal deaths, $4,11,18,19$ it was therefore not surprising that the major indications for transfusion were anemia, $\mathrm{PPH}$, shock and APH. These indications were similar to those from the United States and Canada. ${ }^{15,16}$ The findings that some of the studied subjects had morbidities such as wound infection, puerperal sepsis, anemic heart failure, shock, renal failure, and disseminated intravascular coagulopathy related to blood loss, transfusion reaction, and anemia often arising from difficulties in timely securing the right type of blood product were similar to those noted by other researchers. ${ }^{17,18}$ These were mainly as a result of late presentation to hospital, nonavailability of blood and blood products, cost, and financial handicap as seen in similar studies in Africa. ${ }^{18,19}$ Strict adherence to correct labeling of blood products, as well as crossmatching and administration procedures as done for all the cases we managed is of paramount importance in preventing transfusion reactions, even in emergencies. ${ }^{7}$

Those who had transfusions for mild and moderate anemia were transfused for a coexisting third trimester viable pregnancy close to or at term (35-40 week gestation) with ongoing bleeding from APH or ruptured uteri taking into consideration the recommendations of the departmental protocol which prescribes blood transfusion for this category of patients and also considering the decision-intervention interval of 6-24 hours for emergency surgeries in our center.

The large volume of blood needed to prevent the morbidity and mortality related to blood loss as depicted in this study, places a great demand on the poorly funded blood bank services as well as increases the cost of health care services. ${ }^{11}$ Thus, the need is emphasized for an effective and safe blood transfusion system, which has been shown to be life-saving in both developed and developing countries like Nigeria, where PPH is a major cause of maternal and perinatal morbidity and mortality. ${ }^{3,4,7,11,17-19}$ If blood transfusion services are provided in line with best practices, it will impact positively on our obstetric practice where the major challenges include the fact that patients are made to individually source blood from government or private owned blood banks, as well as the inability of patients to procure this blood which is often sold at exorbitant prices where and when available.
If the world hopes to achieve the goals of the safe motherhood initiatives and millennium development goal five as recommended by the World Health Organization and the United Nations, then we must begin to work on how to optimize the blood transfusion services in our healthcare facilities in order to make blood transfusion safe and effective. This can be achieved by establishing national blood transfusion services within the reach of all, as well as ensuring 24-hour services with availability of safe blood and blood products at all times and at no cost with the aim of making blood safe, accessible, free, and available within the shortest possible time. Individuals should also be encouraged to voluntarily donate blood to stock such banks and every obstetric unit should develop a blood transfusion protocol taking into consideration the specific challenges of the region or locality.

\section{Disclosure}

The authors declare no conflicts of interest in this work.

\section{References}

1. WHO/UNICEF/UNFPA. Maternal Mortality in 2005: Estimates Developed by WHO, UNICEF, UNFPA and The World Bank. Geneva: World Health Organization; 2007. Available from: http://www.who.int/ whosis/mme_2005.pdf. Accessed May 17, 2013.

2. Khan KS, Wojdyla D, Say L, Gülmezoglu AM, Van Look PF. WHO analysis of causes of maternal death: a systematic review. Lancet. 2006;367(9516):1066-1074.

3. Drife J. Management of primary postpartum haemorrhage. $\mathrm{Br} J$ Obstet Gynaecol. 1997;104(3):275-277.

4. World Health Organization. Country Health System Fact Sheet 2006 Nigeria. Available from: http://www.afro.who.int/index.php?. Accessed June 8, 2013.

5. Bankole A. Barriers to Safe Motherhood in Nigeria. New York, NY: Guttmacher Institute; 2009.

6. World Health Organization. Maternal Mortality in 2000: Estimates Developed by WHO, UNICEF, UNFPA. Geneva: World Health Organization; 2004. Available from: http://www.childinfo.org/files/ maternal_mortality_in_2000.pdf. Accessed May 17, 2013.

7. Royal College of Obstetricians and Gynecologists. Blood Transfusions in Obstetrics (Green-top 47). London: Royal College of Obstetricians and Gynecologists; 2008. Available from: http://www.rcog.org.uk/files/ rcog-corp/uploaded-files/GT47BloodTransfusions1207amended.pdf. Accessed June 8, 2013.

8. Ekeroma AJ, Ansari A, Stirrat GM. Blood transfusion in obstetrics and gynaecology. Br J Obstet Gynaecol. 1997;104(3):278-284.

9. Centers for Disease Control and Prevention [homepage on the Internet]. Blood transfusion therapy. Atlanta: Centers for Disease Control and Prevention; 2011. Available from: http://www.cdc.gov/ncbddd/dba/ transfusion.html. Accessed May 17, 2013.

10. A joint WHO/UNFPA/INICEF World bank statement. Reduction of Maternal Mortality. Geneva: World Health Organization; 1999. Available from: http://www.unfpa.org/upload/lib_pub_file/236_ filename_e_rmm.pdf. Accessed May 17, 2013.

11. Kamani AA, McMorland GH, Wadsworth LD. Utilization of red blood cell transfusion in an obstetric setting. Am J Obstet Gynecol. 1988;159(5):1177-1181.

12. Hill T, Lavin P. Blood ordering in obstetrics and gynecology: recommendations for the type and screen. Obstet Gynecol. 1993;62(2): $236-240$. 
13. Combs CA, Murphy EL, Laros RK. Cost-benefit analysis of autologous blood donation in obstetrics. Obstet Gynecol. 1992;80(4): $621-625$.

14. Jose AG, Arturo C, Manuel M. Blood donation and blood transfusion in Spain (1997-2007): the effects of demographic changes and universal leucoreduction. Blood Transfus. 2010;8(2):100-106.

15. Balki M, Dhumne S, Kasodekar S, Seaward G, Carvalho JC. Blood transfusion for primary postpartum hemorrhage: a tertiary care hospital review. J Obstet Gynaecol Can. 2008;30(11):1002-1007.

16. Rouse DJ, MacPherson C, Landon M, et al. Blood transfusion and caesarean delivery. Obstetrics and Gynecology. 2006;108(4):891-897.
17. Okafor LA, Orhue A, Sahu BB. Blood transfusion in obstetrics and gynaecology: pattern, problems and prospects. East Afr Med J. 1986;63(1):63-66.

18. Bates I, Chapotera GK, McKew S, van den Broek N. Maternal mortality in sub-Saharan Africa: the contribution of ineffective blood transfusion services. BJOG. 2008;115(11):1331-1339.

19. Adetoro OO. Maternal mortality - a twelve-year survey at the University of Ilorin Teaching Hospital (U.I.T.H.) Ilorin, Nigeria. Int J Gynaecol Obstet. 1987;25(2):93-98.

\section{Publish your work in this journal}

The International Journal of Women's Health is an international, peerreviewed open-access journal publishing original research, reports, editorials, reviews and commentaries on all aspects of women's healthcare including gynecology, obstetrics, and breast cancer. The manuscript management system is completely online and includes a very quick and fair peer-review system, which is all easy to use. Visit http://www.dovepress.com/testimonials.php to read real quotes from published authors.

Submit your manuscript here: http://www.dovepress.com/international-journal-of-womens-health-journal 